\title{
Avoiding hypoglycemia: a key to success for glucose-lowering therapy in type 2 diabetes
}

This article was published in the following Dove Press journal:

Vascular Health and Risk Management

23 April 2013

Number of times this article has been viewed

\section{Bo Ahrén \\ Department of Clinical Sciences, Lund, Faculty of Medicine, Lund University, Lund, Sweden}

Correspondence: Bo Ahrén

BII BMC, Sölvegatan 19,

22I 84 Lund, Sweden

Tel +46462220758

Fax +46462220757

Email bo.ahren@med.lu.se
Abstract: Type 2 diabetes carries a risk for hypoglycemia, particularly in patients on an intensive glucose control plan as a glucose-lowering strategy, where hypoglycemia may be a limitation for the therapy and also a factor underlying clinical inertia. Glucose-lowering medications that increase circulating insulin in a glucose-independent manner, such as insulin and sulfonylurea therapy, are the most common cause of hypoglycemia. However, other factors such as a delayed or missed meal, physical exercise, or drug or alcohol consumption may also contribute. Specific risk factors for development of hypoglycemia are old age, long duration of diabetes, some concomitant medication, renal dysfunction, hypoglycemia unawareness, and cognitive dysfunction. Hypoglycemia is associated with acute short-term symptoms related to either counterregulation, such as tachycardia and sweating, or to neuroglycopenia, such as irritability, confusion, and in severe cases stupor, coma, and even death. However, there are also long-term consequences of hypoglycemia such as reduced working capacity, weight gain, loss of self-confidence with reduced quality of life, and increased risk for cardiovascular diseases. For both the patients, the health care system, and the society at large, hypoglycemia carries a high cost. Strategies to mitigate the risk of hypoglycemia include awareness of the condition; education of patients, relatives, and health care providers; and selecting appropriate glucoselowering medication that also judges the risk for hypoglycemia to prevent this complication. This article summarizes the current knowledge of hypoglycemia and its consequences with a special emphasis on its consequences for the choice of glucose-lowering therapy.

Keywords: type 2 diabetes, hypoglycemia, treatment, sulfonylurea, incretin therapy, insulin

\section{Hypoglycemia as a factor behind clinical inertia}

Intensive glucose control is an important glucose-lowering strategy in the treatment of type 2 diabetes to reduce the risk for diabetic complications. ${ }^{1}$ Intense glucose lowering is achieved in many patients by a combination of medications, including sulfonylureas and insulin. Although careful titration of insulin therapy and intensive therapy with some sulfonylureas can achieve a good glycemic control without significant risk for hypoglycemia, ${ }^{2-4}$ a common limitation of intensive glucose lowering therapy is an increased risk for hypoglycemia. ${ }^{5,6}$ Consequently, today type 2 diabetes is associated with a substantial incidence rate of hypoglycemia. ${ }^{7,8}$ Hypoglycemia has a negative impact for the well-being of the patients, both in the short-term and the long-term. In addition, hypoglycemia also carries a high cost, not only for the individual patient, but also for the health care system and society at large. ${ }^{9,10}$

The risk for hypoglycemia is also an important factor underlying clinical inertia, which is a key consequence of inadequate glycemic control in patients with 
type 2 diabetes. ${ }^{11}$ Clinical inertia is the failure to advance therapy in patients who are not sufficiently controlled in relation to a glycemic target. ${ }^{11}$ This may be related both to a failure to initiate therapy when needed and to the failure of patients to adhere to the prescribed therapy. ${ }^{12}$ Several factors may underlie clinical inertia, related to the knowledge and attitude of health care providers, organizational factors, and the patients. Fear of hypoglycemia is, however, a common denominator for both health care providers and patients in regard to clinical inertia. Fear of hypoglycemia may prevent health care providers from suggesting intensification of glucose-lowering therapy and may also diminish the desire of patients to adhere to prescribed medication. Therefore, hypoglycemia not only carries the risk of acute symptoms and long-term risk, but may also prevent the use of adequate therapy for glucose control.

\section{Definition of hypoglycemia}

There is no generally accepted criterion for hypoglycemia, which makes it difficult to compare studies in regard to frequency of the condition. The American Diabetes Association (ADA) defines hypoglycemia as plasma glucose at $3.9 \mathrm{mmol} / \mathrm{L}$ or lower, ${ }^{13}$ whereas the European Agency for Evaluation of Medicinal Products used $3.0 \mathrm{mmol} / \mathrm{L}$ as the cutoff value for hypoglycemia. ${ }^{14}$ For most patients, symptoms of hypoglycemia occur in the range of 3.4-3.6 mmol/L and in many clinical trials, a cutoff level of $3.1 \mathrm{mmol} / \mathrm{L}$ is commonly used. It was recently suggested that $3.5 \mathrm{mmol} / \mathrm{L}$ would be a reasonable definition of hypoglycemia, because at this level, a clear glucose counterregulation has usually been stimulated. ${ }^{14}$ There is also a clinical definition of hypoglycemia, in that grade 1 hypoglycemia (mild hypoglycemia) is defined as a hypoglycemic event that is self-treated by the patient, whereas a grade 2 (severe) hypoglycemia requires the assistance of another person to administer therapy (for example glucose or glucagon). ${ }^{13,15}$

It should be emphasized that many events of hypoglycemia observed by patients are not associated with glucose measurements and therefore are defined by the patients according to symptoms rather than a glucose cutoff level. The ADA Workgroup on Hypoglycemia has therefore divided hypoglycemia into five different categories: (1) severe hypoglycemia (an event requiring the assistance of another person regardless of glucose levels), (2) documented symptomatic hypoglycemia (typical symptoms and a confirmed glucose level $\leq 3.9 \mathrm{mmol} / \mathrm{L}$ ), (3) asymptomatic hypoglycemia (glucose level $\leq 3.9 \mathrm{mmol} / \mathrm{L}$ but without typical symptoms), (4) probable symptomatic hypoglycemia (typical symptoms but without confirmation of glucose determination), and (5) relative hypoglycemia (typical symptoms but with a glucose level $>3.9 \mathrm{mmol} / \mathrm{L}) .{ }^{13}$ These different forms of hypoglycemia are of importance from a clinical point of view, since the consequences for choice of and adherence to glucose-lowering therapy in praxis is governed by the patient's symptoms rather than a predefined hypoglycemia cutoff level.

\section{Symptoms and consequences of hypoglycemia \\ Acute symptoms}

The most obvious consequences of hypoglycemia are the acute symptoms, such as tachycardia, shakiness, anxiety, irritability, and hunger, which have a negative impact on the patient's well-being, social activities, and working abilities (Table 1). These symptoms are mainly caused by sympathoadrenal activation, which is a part of the glucose counterregulatory response and initiated at glucose levels $\approx 3.5 \mathrm{mmol} / \mathrm{L}$. More severe hypoglycemia also creates neuroglycopenia, which occurs when glucose levels are below the threshold for sufficient cerebral supply (usually $\leq 3.0 \mathrm{mmol} / \mathrm{L}$ ). Neuroglycopenia results in a characteristic series of symptoms, such as difficulty to concentrate, weakness and dizziness, headache, confusion, blurred vision and slurred speech, seizure, loss of consciousness, and coma. ${ }^{9}$ Severe hypoglycemia may also be associated with increased mortality. For example, it has been shown that severe hypoglycemia due to sulfonylurea carries a $9 \%$ mortality rate. ${ }^{16}$

\section{Reduced quality of life}

An important consequence of hypoglycemia, particularly repeated hypoglycemia, is reduced quality of life, as has been demonstrated. ${ }^{10,17}$ Reduced quality of life in patients who have experienced hypoglycemia may have several causes and signs. A common denominator is fear of a new hypoglycemic episode. In a questionnaire study, approximately $25 \%$ of patients with type 2 diabetes who had experienced mild hypoglycemia $(2.9-4.0 \mathrm{mmol} / \mathrm{L})$ and more than $80 \%$ of patients with severe hypoglycemia $(<2.9 \mathrm{mmol} / \mathrm{L})$ responded "sometimes" or "always" to the question whether they had a fear of recurrent hypoglycemic episodes. ${ }^{18}$ Furthermore, a survey on fear of hypoglycemia showed that patients who had experienced hypoglycemia had a markedly higher fear for a new hypoglycemic event and this increased fear was related to the severity and frequency of hypoglycemia. ${ }^{19}$ This increased fear of a new hypoglycemic episode may in turn result in the deterioration of glycemic control due to a 
Table I Characteristics of hypoglycemia in type 2 diabetes $^{5,9,14}$

\begin{tabular}{|c|c|c|c|c|c|}
\hline Causes & Risk factors & $\begin{array}{l}\text { Counterregulatory } \\
\text { symptoms }\end{array}$ & $\begin{array}{l}\text { Neuroglycopenic } \\
\text { symptoms }\end{array}$ & Consequences & $\begin{array}{l}\text { Cost-driving } \\
\text { factors }\end{array}$ \\
\hline $\begin{array}{l}\text { Medication which increases } \\
\text { circulating insulin } \\
\text { Delayed or missed meal } \\
\text { Ingestion of smaller meal } \\
\text { than planned } \\
\text { Physical exercise } \\
\text { Drug/alcohol consumption } \\
\text { General illness }\end{array}$ & $\begin{array}{l}\text { Old age } \\
\text { Long duration } \\
\text { of diabetes } \\
\text { Concomitant } \\
\text { medication } \\
\text { Renal dysfunction } \\
\text { Hypoglycemia } \\
\text { unawareness } \\
\text { Cognitive dysfunction } \\
\text { Peripheral neuropathy } \\
\text { Intense glucose- } \\
\text { lowering strategy }\end{array}$ & $\begin{array}{l}\text { Tachycardia } \\
\text { Sweating } \\
\text { Shakiness } \\
\text { Anxiety } \\
\text { Dry mouth } \\
\text { Hunger } \\
\text { Pupil dilatation }\end{array}$ & $\begin{array}{l}\text { Difficulty } \\
\text { concentrating } \\
\text { Weakness } \\
\text { Tiredness } \\
\text { Irritability } \\
\text { Headache } \\
\text { Dizziness } \\
\text { Confusion } \\
\text { Altered vision } \\
\text { Slurred speech } \\
\text { Loss of } \\
\text { consciousness } \\
\text { Seizure } \\
\text { Coma } \\
\text { Death }\end{array}$ & $\begin{array}{l}\text { Difficulty keeping/ } \\
\text { obtaining employment } \\
\text { Affects social interactions, } \\
\text { including sport and } \\
\text { leisure activities } \\
\text { Difficulty keeping/ } \\
\text { obtaining driving license } \\
\text { Disturbances in sleep } \\
\text { Emergency department visits } \\
\text { Traffic accidents } \\
\text { Fall with fractures } \\
\text { Deterioration of glycemic } \\
\text { control } \\
\text { Weight gain } \\
\text { Lost self-confidence } \\
\text { Reduced working capacity } \\
\text { Fear of hypoglycemia }\end{array}$ & $\begin{array}{l}\text { Increased burden } \\
\text { on the health } \\
\text { care system } \\
\text { Ambulance, } \\
\text { emergency wards } \\
\text { Hospitalization } \\
\text { costs } \\
\text { Increased use of } \\
\text { strips } \\
\text { Use of glucagon } \\
\text { Low productivity } \\
\text { Absence from } \\
\text { work } \\
\text { Accidents }\end{array}$ \\
\hline
\end{tabular}

decreased desire of the patient for tight glycemic control, reduced aggressiveness of therapy, poorer adherence to diet therapy, and compromised compliance for taking medication. ${ }^{18,20}$ In particular, patients who have had hypoglycemia tend to target a higher night time glucose level due to fear for nocturnal hypoglycemia. All of this may result in deterioration of glycemic control, and hypoglycemia is therefore a risk factor for later hyperglycemia-related complications of diabetes.

\section{Long-term complications}

It has become evident during recent years that hypoglycemia carries serious and long-term consequences. Weight gain is such a consequence, caused by increased eating in self-defense against hypoglycemia. In turn, weight gain has negative impacts on health, such as increased insulin resistance, worsening of metabolic and hemodynamic changes associated with the metabolic syndrome, and deterioration of glycemia. Another serious long-term complication to hypoglycemia is increased risk for cardiovascular diseases, which has been demonstrated in long-term follow-up studies. ${ }^{21,22}$ One such study examined the associations between severe hypoglycemia and the risks of macrovascular or microvascular events and death among 11,140 patients with type 2 diabetes from the ADVANCE study. ${ }^{21}$ It was found that during a median follow-up period of 5 years, severe hypoglycemia was associated with a significantly higher risk of major macrovascular events, major microvascular events, death from a cardiovascular cause, and even death from any cause. Another study demonstrated increased risk for cardiovascular diseases after hypoglycemia in a study population of more than 44,000 patients with type 2 diabetes compared to a control group. ${ }^{22}$ Age of patients, duration of diabetes, and $\mathrm{HbA}_{1 \mathrm{c}}$ did not differ between the groups.

The increased risk for cardiovascular diseases due to hypoglycemia might have several causes. One causal factor may be the weight gain associated with defensive eating, since increased body weight is associated with cardiovascular diseases. Other factors resulting in increased cardiovascular risk after hypoglycemia may be due to catecholamines released locally in the heart during hypoglycemic episodes. This may result in increased heart rate, silent myocardial ischemia, prolonged QT time, and angina and myocardial infarction. ${ }^{23-25}$ There is also increased thrombotic tendency with decreased thrombolysis, endothelial dysfunction with reduced vasodilatation, and inflammation due to cytokine release in association with hypoglycemia. ${ }^{23}$

Hypoglycemia is also associated with other negative long-term consequences. One such consequence is the development of cognitive dysfunction and dementia. ${ }^{26,27}$ Hence, hypoglycemia not only carries short-term risks, but may also be associated with increased long-term risk for various complications.

\section{Incidence of hypoglycemia}

Several factors make it difficult to establish the incidence rate of hypoglycemia in type 2 diabetes. One factor is that the incidence of hypoglycemia in type 2 diabetes is related to the aggressiveness of the therapy, as recently demonstrated in a meta-analysis of large clinical trials 
showing that intensive glucose-lowering therapy increased the risk for hypoglycemia by more than $100 \% .{ }^{28}$ Another factor is that reports of hypoglycemia may depend on cut-off levels for glucose, which may be different in different studies, or by patients reporting symptomatic non-confirmed hypoglycemia, the definition of which is dependent on patient choice and therefore is different between patients. A third factor is that many events of hypoglycemia go undetected. Thus, one study using continuous glucose monitoring to estimate hypoglycemic episodes reported that approximately $50 \%$ of patients had unrecognized hypoglycemic events. ${ }^{29}$ This hypoglycemia unawareness is a clinical reality defined by the failure of the patient to recognize a hypoglycemic episode. ${ }^{30}$ Furthermore, patients may also refrain from reporting hypoglycemic episodes, since the hypoglycemic events are either forgotten, taken naturally, or simply not reported, the latter of which may be due to the fear that reporting hypoglycemic episodes might have a negative impact on, for example, employment or the ability to keep a driving license. It has been reported that only approximately $15 \%$ of hypoglycemic episodes in patients with type 2 diabetes were reported to the doctor. ${ }^{18}$

Some data, however, exist in regard to the hypoglycemia incidence rate in clinical practice. The UK Hypoglycemia Study Group reported that 39\% of patients treated with sulfonylurea, $51 \%$ of patients treated with insulin for less than 2 years, and $64 \%$ of patients treated with insulin for more than 5 years experienced hypoglycemia during a study period of $8-10$ months. $^{7}$ Furthermore, $7 \%$ of patients treated with sulfonylurea or insulin for less than 2 years and $25 \%$ of patients treated with insulin for more than 5 years had experienced severe hypoglycemia. ${ }^{7}$ Moreover, a population-based study exploring hypoglycemia over a 1 -month period revealed an annual rate of hypoglycemia in insulin-treated patients with type 2 diabetes of 0.35 events per patient. ${ }^{8}$ In addition, one study demonstrated that $25 \%$ of patients treated with insulin had at least one episode of severe hypoglycemia every year. ${ }^{31}$ An epidemiological study reported that hypoglycemia occurred in $16 \%$ of patients with type 2 diabetes treated with sulfonylureas over a mean period of 7 months. ${ }^{32}$ One study reported that severe hypoglycemia occurred annually in $0.8 \%$ of patients treated with sulfonylurea and $7 \%$ of patients treated with insulin. ${ }^{33}$ More studies are required, however, for establishing the incidence of hypoglycemia in different patient populations, and these studies need uniform protocols regarding reporting and definitions.

\section{Risk factors for hypoglycemia}

Table 1 summarizes the most common causes and risk factors for hypoglycemia in patients with type 2 diabetes. The most common cause is the use of glucose-lowering medication, which increases circulating insulin in a glucose-independent manner. Sulfonylureas and insulin are of particular importance in this context. ${ }^{34}$ However, other factors apart from medication contribute to increased risk for hypoglycemia. One such factor is delayed or missed meal intake or ingestion of a smaller meal than planned. It has actually been shown that subjects with regular eating habits have a lower risk for hypoglycemia than patients who have irregular eating habits. ${ }^{9}$ Furthermore, people undertaking fasting, such as during Ramadan, have an increased risk of hypoglycemia during these periods. ${ }^{35}$ Increased physical exercise also carries an increased risk of hypoglycemia due to increased insulin sensitivity. Moreover, drug or alcohol consumption may cause hypoglycemia, particularly in conjunction with glucose-lowering agents, since it delays glucose counterregulation. ${ }^{13}$ These causes of hypoglycemia may be of particular importance in certain patient groups, which therefore have an increased risk for hypoglycemia. One such risk factor for hypoglycemia is old age.$^{36}$ Increased risk for hypoglycemia in elderly subjects may be due to increased sensitivity to medication and compromised counterregulation. Also, long duration of diabetes, renal dysfunction, peripheral neuropathy, obesity, hypoglycemia unawareness, and cognitive dysfunction increase the risk for hypoglycemia. ${ }^{6,737,38}$ In addition, some medications, such as angiotensin-converting enzyme (ACE) inhibitors and betablockers, may mask the symptoms of hypoglycemia, thereby aggravating a hypoglycemic event, and some medication will increase circulating concentrations of sulfonylurea which increases the risk for hypoglycemia in patients treated with sulfonylureas. These agents include those which inhibit renal excretion of sulfonylurea (aspirin and allopurinol), displace sulfonylureas from albumin (aspirin, warfarin, sulphonamide, trimethoprim, and fibrates), or reduce metabolism of sulfonylurea (warfarin and mono-amine oxidase inhibitors), as reviewed by Amiel et al. ${ }^{14}$

\section{Cost of hypoglycemia}

Hypoglycemia is associated with a high cost for the patient, the health care system, and society at large. ${ }^{9}$ Table 1 lists some of the cost-driving factors induced by hypoglycemia. For example, $25 \%$ of hospital admissions in elderly patients are due to severe hypoglycemia ${ }^{39}$ and $95 \%$ of emergency visits due to drug adverse events within endocrinology are due to hypoglycemia, and these emergency visits carry a high cost. ${ }^{40}$ 
Other costs related to hypoglycemia are an increased burden on the health care system, including telephone consultations, hospitalization costs, ${ }^{9,41}$ and increased use of strips for the self-monitoring of blood glucose,${ }^{31}$ as well as use of glucose or glucagon administration. Hypoglycemia may also result in absence from work and reduced productivity ${ }^{31}$ and accidents. ${ }^{42}$ Attempts to estimate the total cost of hypoglycemia for the health care system have arrived at very high cost. ${ }^{9,43}$ To this estimated cost will be added the reduced quality of life, reduced or even lost work capacity, ${ }^{44}$ and increased long-term complications. Thus, it is clear that hypoglycemia carries a financial burden at several levels of society and therefore that strategies to mitigate the risk for hypoglycemia will be cost-saving strategies.

\section{Implications for prevention and therapy of hypoglycemia}

The high frequency of hypoglycemia in type 2 diabetes and its important consequences, including the high cost, imply that it is of importance to develop strategies to mitigate the risk of hypoglycemia. Such strategies should involve increasing the awareness of hypoglycemia and its mechanisms and symptoms among patients, relatives, health care providers, and society at large. Such awareness should also include knowledge of causes and risk factors for hypoglycemia. A second strategy should be educating the patients, relatives, and health care providers about hypoglycemia. This includes teaching about symptoms, risk factors, and self-glucosemonitoring so that food or glucose ingestion may be initiated when glucose levels are low. It is also important to increase knowledge among patients, relatives, and the surrounding society about how to handle glucagon for injection in cases of severe hypoglycemia. An interesting educational program was recently reported from the UK. ${ }^{45}$ A third strategy to prevent and avoid hypoglycemia is to make the focus of glucoselowering therapy include lowering the risk of hypoglycemia in addition to improving glycemic control.

Therapies which carry a low risk of hypoglycemia might do so due to a glucose-dependent mechanism to increase circulating insulin levels in combination with effects to prevent and protect from hypoglycemia by supporting physiological glucose counterregulation, which is triggered by reducing glucose to the range of 3.6-4.0 $\mathrm{mmol} / \mathrm{L}$. This counterregulation involves several counter-regulatory hormones. Figure 1 illustrates the most important glucose counterregulatory mechanisms: inhibition of insulin secretion from $\beta$-cells (occurs at $\approx<4 \mathrm{mmol} / \mathrm{L}$ ); stimulation of glucagon, adrenaline, and cortisol secretion; and activation

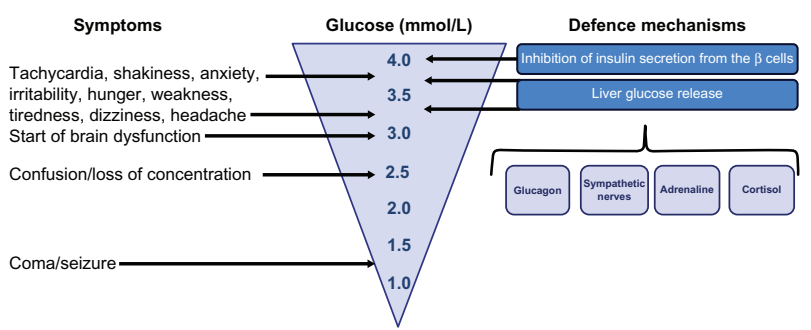

Figure I Symptoms and defence mechanisms in relation to glucose levels in the subnormal range.

of the sympathetic nerves (occurs usually at glucose levels $\approx<3.6-3.9 \mathrm{mmol} / \mathrm{L})$, which increase liver glucose output. Rapid glucagon counterregulation is of marked importance to defend and combat acute hypoglycemia, and this is dependent on reduced intra-islet insulin levels, a direct action of low glucose on $\alpha$-cells, activation of the autonomic nerves, and stimulation by adrenaline released from the adrenals (Figure 2). ${ }^{46,47}$

\section{Glucose-lowering medication and hypoglycemia \\ Metformin}

First-line pharmacological glucose-lowering therapy in most guidelines is metformin. It has been used for more than 50 years and, although its detailed mechanism of action is still not established, it increases insulin sensitivity and reduces hepatic glucose production. ${ }^{48}$ When used as monotherapy, it carries a low risk of hypoglycemia. In the UKPDS, which was a long-term study, the risk for mild hypoglycemia in patients treated with metformin as monotherapy was only $0.3 \%$ per year. ${ }^{20}$ Similarly, several clinical trials have shown that the risk for mild hypoglycemia in patients on metformin alone is very low, with no risk for severe hypoglycemia. ${ }^{71-77}$

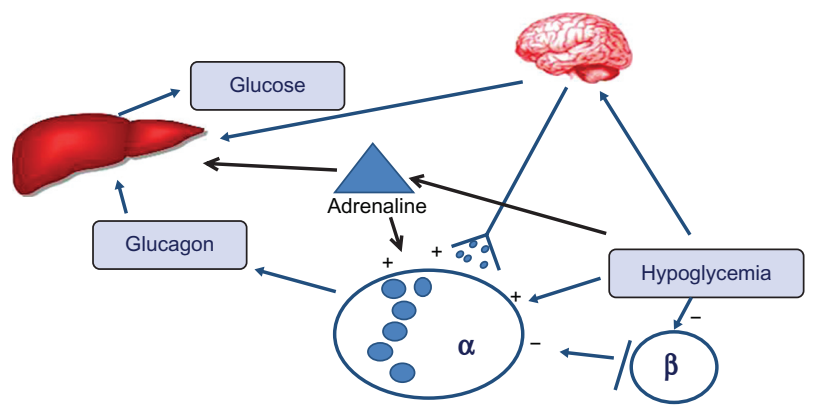

Figure 2 Mechanisms of glucose counterregulation.

Note: Glicagon is secreted from the islet alpha cells in response to hypoglycemia to stimulate glucose production from the liver which raises circulating glucose. Glucagon secretion is stimulated during hypoglycemia by reduced insulin secretion from beta cells, direct action of low glucose on alpha cells, activation of the autonomic nerves and by adrenaline released from the adrenals. 
Table 2 Incidence rates of grade I hypoglycemia in placebocontrolled 26-30 week clinical trials in which incretin therapy or placebo has been added to ongoing metformin

\begin{tabular}{lll}
\hline Study group & Hypoglycemia & References \\
\hline Exenatide + metformin & $5.3 \%$ & 71 \\
Metformin + placebo & $5.3 \%$ & 72 \\
Liraglutide + metformin & $3.0 \%$ & \\
Metformin + placebo & $3.0 \%$ & 73 \\
Sitagliptin + metformin & $1.3 \%$ & \\
Metformin + placebo & $2.1 \%$ & 74 \\
Saxagliptin + metformin & $0.5 \%$ & \\
Metformin + placebo & $0.6 \%$ & 75 \\
Vildagliptin + metformin & $0.5 \%$ & \\
Metformin + placebo & $0.5 \%$ & 76 \\
Alogliptin + metformin & $0.0 \%$ & \\
Metformin + placebo & $1.0 \%$ & 77 \\
Linagliptin + metformin & $0.6 \%$ & \\
Metformin + placebo & $2.8 \%$ &
\end{tabular}

Notes: In none of the reported studies, was there a single case of grade 2 hypoglycemia. Percentage refers to the percentage of patients with at least one hypoglycemic episode during the study period.

Table 2 shows the frequency of hypoglycemia in 6-month trials on patients treated with metformin. Since metformin increases insulin sensitivity, it may carry an increased risk when combined with agents increasing insulin levels, such as sulfonylurea or exogenous insulin.

\section{Sulfonylurea}

When metformin is insufficient to reduce glycemia when given in monotherapy, sulfonylureas may be added. Sulfonylureas have been used for more than 50 years and they potently stimulate insulin secretion through a glucoseindependent mechanism on pancreatic $\beta$-cells, thereby increasing circulating insulin levels. ${ }^{49}$ This results in a good glucose-lowering ability, but hypoglycemia is a common adverse event. ${ }^{7,19,33}$ It should be emphasized that there is a difference in the risk of hypoglycemia with different sulfonylureas, with the newer forms (gliclazide, glimepiride, and glipizide) having a lower risk than the first and second generations of sulfonylureas (tolbutamide and glibenclamide). ${ }^{4,50,51}$ This higher risk for hypoglycemia with the older generations of sulfonylureas might be explained by their action to stimulate $\beta$-cell function over a long period of time and at low glucose in combination with compromised glucagon counterregulation during hypoglycemia. Therefore, sulfonylureas may inhibit glucose counterregulation, as has been demonstrated for the older generation sulfonylureas, tolbutamide $^{52}$ and glibenclamide. ${ }^{53}$

\section{Thiazolidinediones}

Thiazolidinediones have been used as a second- or thirdline therapy since the end of the 1990s. They act by sen- sitizing muscle, adipose tissue, and the liver to insulin and have been shown to efficiently reduce glycemia. ${ }^{48}$ Thiazolidinediones carry a similar risk for hypoglycemia as metformin and lower than sulfonylureas. This was clearly demonstrated in the ADOPT (diabetes outcome progression trial) study, in which monotherapy with rosiglitazone, metformin, and glibenclamide was examined over a 4-year study period: hypoglycemia occurred in approximately $10 \%$ of patients on rosiglitazone versus $12 \%$ of patients on metformin and more than $38 \%$ of patients on glibenclamide. ${ }^{54}$

\section{Alpha glucosidase inhibitors}

Alpha glucosidase inhibitors reduce glucose by inhibiting glucose uptake into the circulation after meal ingestion due to inhibition of the intestinal brush border enzyme $\alpha$-glucosidase, which results in delayed hydrolysis of ingested polysaccharides and oligosaccharides. ${ }^{55}$ They are used either as monotherapy or as an add-on to metformin and reduce glucose. Since these inhibitors do not increase insulin levels, the risk for hypoglycemia is low. ${ }^{55}$

\section{Incretins}

Another option to add to metformin is incretin therapy, which is based on the glucose-lowering action of the gut incretin hormone glucagon-like peptide-1 (GLP-1) and used either as injectable agonists of the GLP-1 receptor ${ }^{56}$ or oral tablets which inhibit dipeptidyl peptidase-4 (DPP-4), the enzyme which inactivates GLP-1 ${ }^{57}$ Both GLP-1 receptor agonists and DPP-4 inhibitors have a low risk for hypoglycemia (Table 2). ${ }^{58}$ This is due to a combination of a glucose-dependent stimulation of insulin secretion by GLP- $1^{59}$ and a preserved glucagon counterregulation to hypoglycemia as shown both for the GLP-1 receptor agonist exenatide ${ }^{60}$ and the DPP-4 inhibitor vildagliptin. ${ }^{61}$ Incretin therapy is also associated with a low risk of hypoglycemia when added to insulin therapy as has been demonstrated in several studies both for GLP-1 receptor agonists $^{62-64}$ and DPP-4 inhibitors. ${ }^{65-67}$

\section{Insulin}

Careful titration of insulin therapy can achieve a good glycemic control without significant risk for hypoglycemia. ${ }^{2,3}$ However, in clinical practice, insulin treatment is usually associated with a high risk of hypoglycemia in type 2 diabetes $^{7,31,68}$ and may even result in omission or non-adherence to the therapy. ${ }^{69}$ It should be emphasized that more modern insulin types are associated with a lower risk of hypoglycemia than older insulins. Thus, it has been shown that long-acting insulin analogues have a lower risk for hypoglycemia than mediumacting neutral protamine Hagedorn (NPH) insulin. ${ }^{70}$ 


\section{Conclusion}

Hypoglycemia is common not only in type 1 diabetes, but also in type 2 diabetes. It has negative consequences for both the daily life and well-being of the patient, for the glycemic control of diabetes, and for long-term risk of complications. Hypoglycemia is also associated with a high cost for the patient, the health care system, and society at large. The mitigation of the risk of hypoglycemia should include a strategy of increasing awareness of the risk; education of patients, relatives, and health care providers; and a careful choice of glucose-lowering medication taking into consideration the risk for hypoglycemia when selecting the therapy for the individual patient.

\section{Disclosure}

The author has received honoraria for lecturing and membership in advisory boards for Bristol Myers Squibb, GlaxoSmithKline, Lilly, Novartis, Novo Nordisk, Merck, AstraZeneca, and Sanofi-Aventis, all of which are companies producing GLP-1 receptor agonists or DPP-4 inhibitors. The author reports no other conflicts of interest in this work.

\section{References}

1. Holman RR, Paul SK, Bethel MA, Matthews DR, Neil HA. 10-year follow-up of intensive glucose control in type 2 diabetes. NEngl J Med 2008;359(15):1577-1589.

2. Rosenstock J, Dailey G, Massi-Benedetti M, Fritsche A, Lin Z, Salzman A. Reduced hypoglycemia risk with insulin glargine: a metaanalysis comparing insulin glargine with human NPH insulin in type 2 diabetes. Diabetes Care. 2005;28(4):950-955.

3. Barnett A. Dosing of insulin glargine in the treatment of type 2 diabetes. Clin Ther. 2007;29(6):987-999.

4. Zoungas S, Chalmers J, Kengne AP, et al. The efficacy of lowering glycated haemoglobin with a gliclazide modified release-based intensive glucose lowering regimen in the ADVANCE trial. Diabet Res Clin Pract. 2010;89(2):126-133.

5. Briscoe VJ, Danis SN. Hypoglycemia in type 1 and type 2 diabetes: physiology, pathophysiology and management. Clin Diabetes. 2006; 24(3):115-121.

6. Cryer PE. Hypoglycemia: the limiting factor in the glycemic management of type I and type II diabetes. Diabetologia. 2002;45(7):937-948.

7. UK Hypoglycemia Study Group. Risk of hypoglycemia in types 1 and 2 diabetes: effects of treatment modalities and their duration. Diabetologia. 2007;50(6):1140-1147.

8. Donnelly LA, Morris AD, Frier BM, et al. Frequency and predictors of hypoglycemia in type 2 and insulin-treated type 2 diabetes: a populations-based study. Diabet Med. 2005;22(6):749-755.

9. Barnett AH, Cradock S, Fisher M, Hall G, Hughes E, Middleton A. Key consideration around the risks and consequences of hypoglycemia in people with type 2 diabetes. Int J Clin Pract. 2010;64(8):1121-1129.

10. Barendse S, Singh H, Frier BM, Speight J. The impact of hypoglycemia on quality of life and related patient-reported outcomes in type 2 diabetes: a narrative review. Diabet Med. 2012;29(3):293-302.

11. Nicolucci A, Rossi MC. Incretin-based therapies: a new potential treatment approach to overcome clinical inertia in type 2 diabetes. Acta Biomed. 2008;79(3):184-191.

12. Bailey CJ, Kodack M. Patient adherence to medication requirements for therapy of type 2 diabetes. Int J Clin Pract. 2011;65(3): 314-322.
13. Workgroup on hypoglycemia, American Diabetes Association. Defining and reporting hypoglycemia in diabetes: a report from the American Diabetes Association Workgroup on Hypoglycemia. Diabetes Care. 2005;28(5):1245-1249.

14. Amiel SA, Dixon T, Mann R, Jameson K. Hypoglycemia in type 2 diabetes. Diabet Med. 2008;25(3):245-254.

15. Zammitt NN, Frier BM. Hypoglycemia in type 2 diabetes: pathophysiology, frequency, and effects of different treatment modalities. Diabetes Care. 2005;28(12):2948-2961.

16. Campbell IW. Metformin and the sulphonylureas: the comparative risk. Horm Metab Res Suppl. 1985;15:105-111.

17. Jermendy G, Erdesz D, Nagy L, et al; Hungarian RECAP Group. Outcomes of adding second hypoglycemia drug after metformin monotherapy failure among type 2 diabetes in Hungary. Health Qual Life Outcomes. 2008;6:88.

18. Leiter LA, Yale JF, Chiasson JL, Harris S, Kleinstiver P, Sauriol L. Assessment of the impact of fear of hypoglycemic episodes on glycemic and hypoglycemia management. Can J Diabet. 2005;29(3): 186-192.

19. Currie CJ, Morgan CL, Poole CD, Sharplin P, Lammert M, McEwan P. Multivariate models of health-related utility and the fear of hypoglycemia in people with diabetes. Curr Med Res Opin. 2006;22(8): 1523-1534.

20. Wright AD, Cull CA, Macleod KM, Holman RR; UKPDS Group. Hypoglycemia in type 2 diabeteic patients randomized to and maintained on monotherapy with diet, sulfonylurea, metformin, or insulin for 6 years from diagnosis: UKPDS73. J Diabetes Complications. 2006; 20(6):395-401.

21. Zoungas S, Patel A, Chalmers J, et al; ADVANCE Collaborative Group. Severe hypoglycemia and risks of vascular events and death. $N$ Engl J Med. 2010;363(15):1410-1418.

22. Zhao Y, Campbell CR, Fonseca V, Shi L. Impact of hypoglycemia associated with antihyperglycemic medications on vascular risks in veterans with type 2 diabetes. Diabetes Care. 2012;35(5): 1126-1132.

23. Desouza CV, Bolli GB, Fonseca V. Hypoglycemia, diabetes, and cardiovascular events. Diabetes Care. 2010;33(6):1389-1394.

24. Nordin C. The case for hypoglycemia as a proarrhythmic event: basic and clinical evidence. Diabetologia. 2010;53(8):1552-1561.

25. Landstedt-Hallin L, Englund A, Adamson U, Lins PE. Increased QT dispersion during hypoglycemia in patients with type 2 diabetes mellitus. J Intern Med. 1999;246(3):299-307.

26. Halimi S. Acute consequences of hypoglycemia in diabetic patients. Diabetes Metab. 2010;36 Suppl 3:S75-S83.

27. Bauduceau B, Doucet J, Bordier L, Garcia C, Dipuy O, Mayaudon H. Hypoglycemia and dementia in diabetic patients. Diabetes Metab. 2010; 36 Suppl 3:S106-S111.

28. Control Group, Turnbull FM, Abraira C, et al. Intensive glucose control and microvascular outcomes in type 2 diabetes. Diabetologia. 2009;52(11):2288-2298.

29. Chico A, Vidal-Rios $\mathrm{P}$, Subirà M, Novials A. The continuous glucose monitoring system is useful for detecting unrecognized hypoglycemias in patients with type 1 and type 2 diabetes but is not better than frequent capillary glucose measurements for improving metabolic control. Diabetes Care. 2003;26(4):1153-1157.

30. Bakatselos SO. Hypoglycemia unawareness. Diabetes Res Clin Pract. 2011;93 Suppl 1:S92-S96.

31. Henderson JN, Allen KV, Deary IJ, Frier BM. Hypoglycemia in insulintreated type 2 diabetes: frequency, symptoms and impaired awareness. Diabet Med. 2003;20(12):1016-1021.

32. Miller CD, Phillips LS, Ziemer DC, Gallina DL, Cook CB, El-Kebbi IM. Hypoglycemia in patients with type 2 diabetes mellitus. Arch Intern Med. 2001;161(13):1653-1659.

33. Leese GP, Wang J, Broomhall J, et al; DARTS/MEMO Collaboration. Frequency of severe hypoglycemia requiring emergency treatment in type 1 and type 2 diabetes: a population-based study of health service resource use. Diabetes Care. 2003;26(4): 1176-1180. 
34. Nathan DM, Buse JB, Davidson MB, et al; American Diabetes Association; European Association for Study of Diabetes. Medical management of hyperglycemia in type 2 diabetes: a consensus algorithm for the initiation and adjustment of therapy: a consensus statement of the American Diabetes Association and the European Association for the Study of Diabetes. Diabetes Care. 2009;32(1):193-203.

35. Salti I, Bénard R, Detournay B, et al; EPIDIAR study group. A population-based study of diabetes and its characteristics during the fasting month of Ramadan in 13 countries: results of the epidemiology of diabetes and Ramadan 1422/2001 (EPIDIAR study). Diabetes Care. 2004;27(10):2306-2311.

36. Holstein A, Hammer C, Hahn M, Kilamadayil NS, Kovacs P. Severe sulfonylurea-induced hypoglycemia: a problem of uncritical prescription and deficiencies of diabetes care in geriatric patients. Expert Opin Drug Saf. 2010;9(5):675-681.

37. Punthake Z, Miller ME, Launer LJ, et al; ACCORD Group of Investigators; ACCORD-MIND Investigators. Poor cognitive function and risk of severe hypoglycemia in type 2 diabetes: post hoc epidemiologic analysis of the ACCORD trial. Diabetes Care. 2012;35(4): 787-793.

38. Schejter YD, Turvall E, Ackerman Z. Characteristic of patients with sulphonylurea-induced hypoglycemia. JAm Med Dir Assoc. 2012;13(3): 234-238.

39. Greco D, Angileri G. Drug-induced severe hypoglycemia in type 2 diabetic patients aged 80 years or older. Diabetes Nutr Metab. 2004; 17(1):23-26.

40. Budnitz DS, Lovegrove MC, Shehab N, Richards CL. Emergency hospitalizations for adverse drug events in older Americans. $N$ Engl J Med. 2011;365(21):2002-2012.

41. Jönsson L, Bolinder B, Lundkvist J. Cost of hypoglycemia in patients with type 2 diabetes in Sweden. Value Health. 2006;9(3):193-198.

42. Frier BM. How hypoglycemia can affect the life of a person with diabetes. Diabetes Metab Res Rev. 2008;24(2):87-92.

43. Quilliam BJ, Simeone JC, Ozbay AB, Koqut SJ. The incidence and costs of hypoglycemia in type 2 diabetes. Am J Manag Care. 2011;17(10): 673-680.

44. Brod M, Christensen T, Thomsen TL, Bushnell DM. The impact of non-severe hypoglycemic events on work productivity and diabetes management. Value Health. 2011;14(5):665-671.

45. Crasto W, Jarvis J, Khunti K, et al. Multifactorial intervention in individuals with type 2 diabetes and microalbuminuria: the Microalbuminuria Education and Medication Optimisation (MEMO) study. Diabet Res Clin Pract. 2011;93(3):328-336.

46. Cryer BE. Glucagon in the pathogenesis of hypoglycemia and hyperglycemia in diabetes. Endocrinology. 2012;153(3):1039-1048.

47. Taborsky GJ Jr, Mundinger TO. Minireview: The role of the autonomic nervous system in mediating the glucagon response to hypoglycemia. Endocrinology. 2012;153(3):1055-1062.

48. Natali A, Ferrannini E. Effects of metformin and thiazolidinediones on suppression of hepatic glucose production and stimulation of glucose uptake in type 2 diabetes: a systematic review. Diabetologia. 2006; 49(3):434-441.

49. Rendell M. The role of sulphonylureas in the management of type 2 diabetes mellitus. Drugs. 2004;64(12):1339-1358.

50. Seino S, Takahashi H, Takahashi T, Shibasaki T. Treating diabetes today: matter of selectivity of sulphonylureas. Diabetes Obes Metab. 2012;14 Suppl 1:9-13.

51. Stahl M, Berger W. Higher incidence of severe hypoglycemia leading to hospital admission in type 2 diabetic patients treated with long-acting versus short-acting sulphonylureas. Diabet Med. 1999;16(7):586-590.

52. Peacey SR, Rostami-Hodjegan A, George E, Tucker GT, Helkler SR. The use of tolbutamide-induced hypoglycemia to examine the intraislet role of insulin in mediating glucagon release in normal humans. $J$ Clin Endocrinol Metab. 1997;82(5):1458-1461.

53. Landstedt-Hallin L, Adamson U, Lins PE. Oral glibenclamide suppresses glucagon secretion during insulin-induced hypoglycemia in patients with type 2 diabetes. J Clin Endocrinol Metab. 1999;84(9): $3140-3145$
54. Kahn SE, Haffner SM, Heise MA, et al; ADOPT Study Group. Glycemic durability of rosiglitazone, metformin or glyburide monotherapy. $N$ Engl J Med. 2006;355(23):2427-2443.

55. Scheen AJ. Clinical efficacy of acarbose in diabetes mellitus: a critical review of controlled trials. Diabet Med. 1998;24(4):311-320.

56. Meier JJ. GLP-1 receptor agonists for individualized treatment of type 2 diabetes mellitus. Nat Rev Endocrinol. 2012;8(12):728-742.

57. Ahrén B. DPP-4 inhibitors. Best Pract Res Clin Endocrinol Metab. 2007;21(4):517-533.

58. Ahrén B. GLP-1 for type 2 diabetes. Exp Cell Res. 2011;317(9): $1239-1245$

59. Ahrén B, Larsson H, Holst JJ. Effects of glucagon-like peptide-1 on islet function and insulin sensitivity in noninsulin-dependent diabetes mellitus. J Clin Endocrinol Metab. 1997;82(2):473-478.

60. Degn KB, Brock B, Juhl CB, et al. Effect of intravenous infusion of exenatide (synthetic exendin-4) on glucose-dependent insulin secretion and counterregulation during hypoglycemia. Diabetes. 2004;53(9):2397-2403.

61. Ahrén B, Schweizer A, Dejager S, et al. Vildagliptin enhances islet responsiveness to both hyper- and hypoglycemia in patients with type 2 diabetes. J Clin Endocrinol Metab. 2009;94(4):1236-1243.

62. DeVries JH, Bain SC, Rodbard HW, et al; Liraglutide-Detemir Study Group. Sequential intensification of metformin treatment in type 2 diabetes with liraglutide followed by randomized addition of basal insulin prompted by A1C targets. Diabetes Care. 2012;35(7):1446-1454.

63. Rosenstock J, Ahrén B, Chow F, et al. Once-weekly GLP-1 receptor agonist albiglutide vs titrated prandial lispro added on to titrated basal glargine in type 2 diabetes (T2D) uncontrolled on glargine plus oral agents: similar glycemic control weight loss and less hypoglycemia. Diabetes. 2012;61 Suppl 1:A15.

64. Aronson R, Riddle M, Home P, et al. Efficacy and safety of once-daily lixisenatide in type 2 diabetes insufficiently controlled with basal insulin \pm metformin: GetGoal-L study. Diabetologia. 2012;55 Suppl 1:S8

65. Fonseca V, Schweizer A, Albrecht D, Baron MA, Chang I, Dejager S. Addition of vildagliptin to insulin improves glycemic control in type 2 diabetes. Diabetologia. 2007;50(6):1148-1155.

66. Vilsbøll T, Rosenstock J, Yki-Järvinen H, et al. Efficacy and safety of sitagliptin when added to insulin therapy in patients with type 2 diabetes. Diabetes Obes Metab. 2010;12(2):167-177.

67. Barnett AH, Charbonnel B, Donovan M, Fleming D, Chen R. Effect of saxagliptin as add-on therapy in patients with poorly controlled type 2 diabetes on insulin alone or insulin combined with metformin. Curr Med Res Opin. 2012;28(4):513-523.

68. Budnitz DS, Lovegrove MC, Shehab N, Richards CL. Emergency hospitalizations for adverse drug events in older Americans. $N$ Engl J Med. 2011;365(21):2002-2012.

69. Peyrot M, Barnett AH, Meneghini LF, Schumm-Draeger PM. Factors associated with injection omission/non-adherence in the Global Attitudes of Patients and Physicians in Insulin Therapy study. Diabetes Obese Metab. In press 2012.

70. Little S, Shaw J, Home P. Hypoglycemia rates with basal insulin analogs. Diabetes Technol Ther. 2011;13 Suppl 1:S53-S64.

71. DeFronzo RA, Rattner RE, Han J, Kim DD, Fineman MS, Baron AD. Effects of exenatide (exendin-4) on glycemic control and weight over 30 weeks in metformin-treated patients with type 2 diabetes. Diabetes Care. 2005;28(5):1092-1100.

72. Nauck M, Frid A, Hermansen K, et al; LEAD-2 Study Group. Efficacy and safety comparison of liraglutide, glimepiride, and placebo, all in combination with metformin, in type 2 diabetes: the LEAD (liraglutide effect and action in diabetes)-2 study. Diabetes Care. 2009;32(1): 84-90.

73. Charbonnel B, Karasik A, Liu J, Wu M, Meininger G; Sitagliptin Study 020 Group. Efficacy and safety of the dipeptidyl peptidase-4 inhibitor sitagliptin added to ongoing metformin therapy in patients with type 2 diabetes inadequately controlled with metformin alone. Diabetes Care. 2006;29(12):2638-2643.

74. DeFronzo RA, Hissa MN, Garber AJ, et al; Saxagliptin 014 Study Group. The efficacy and safety of saxagliptin when added to metformin therapy in patients with inadequately controlled type 2 diabetes with metformin alone. Diabetes Care. 2009;32(9):1649-1655. 
75. Bosi E, Camisasca RP, Collober C, Rochotte E, Garber AJ. Effects of vildagliptin on glucose control over 24 weeks in patients with type 2 diabetes inadequately controlled with metformin. Diabetes Care. 2007;30(4):890-895.

76. Nauck MA, Ellis GC, Fleck PR, Wilson CA, Mekki Q; Alogliptin Study 008 Group. Efficacy and safety of adding the dipeptidyl peptidase-4 inhibitor alogliptin to metformin therapy in patients with type 2 diabetes inadequately controlled with metformin monotherapy: a multicenter, randomized, double-blind, placebo-controlled study. Int J Clin Pract. 2009;63(1):46-55.
77. Taskinen MR, Rosenstock J, Tamminen I, et al. Safety and efficacy of linagliptin as add-on therapy to metformin in patients with type 2 diabetes: a randomized, double-blind, placebo-controlled study. Diabetes Obes Metab. 2011;13(1):65-74.

\section{Publish your work in this journal}

Vascular Health and Risk Management is an international, peerreviewed journal of therapeutics and risk management, focusing on concise rapid reporting of clinical studies on the processes involved in the maintenance of vascular health; the monitoring, prevention and treatment of vascular disease and its sequelae; and the involvement of metabolic disorders, particularly diabetes. This journal is indexed on PubMed Central and MedLine. The manuscript management system is completely online and includes a very quick and fair peer-review system, which is all easy to use. Visit http://www.dovepress.com/ testimonials.php to read real quotes from published authors.

Submit your manuscript here: http://www.dovepress.com/vascular-health-and-risk-management-journal 